\title{
Removal of chlorinated organic pollutants from groundwater using V-UV based advanced oxidation process
}

\author{
Debra Barki, Sara Sabach, Yael Dubowski
}

Faculty of Civil and Environmental Engineering, Technion, Israel

\section{Supporting Information}

Table S1: groundwater characterization from Jerusalem drilling

\begin{tabular}{|l|r|l|}
\hline $\mathrm{pH}$ & 7.49 & \\
\hline conductivity & 95.1 & $\mu \mathrm{S}$ \\
\hline & & \\
\hline optical density $405 \mathrm{~nm}$ & 0 & {$[\mathrm{~A}]$} \\
\hline optical density $205 \mathrm{~nm}$ & 0.003 & {$[\mathrm{~A}]$} \\
\hline & & \\
\hline alkalinity & 225 & $\begin{array}{l}{\left[\mathrm{mg} \mathrm{L}^{-1}\right.} \\
\left.\mathrm{CaCO}_{3}\right]\end{array}$ \\
\hline & & {$\left[\mathrm{mg} \mathrm{L}^{-1}\right.$} \\
total hardness & 285 & $\left.\mathrm{CaCO}_{3}\right]$ \\
\hline & & \\
\hline $\mathrm{F}^{-}$ & 0.66 & $\mathrm{mg} \mathrm{L}^{-1}$ \\
\hline $\mathrm{Cl}^{-}$ & 35.95 & $\mathrm{mg} \mathrm{L}^{-1}$ \\
\hline $\mathrm{ClO}_{3}{ }^{-}$ & 0.14 & $\mathrm{mg} \mathrm{L}^{-1}$ \\
\hline $\mathrm{NO}_{3}{ }^{-}$ & 17.8 & $\mathrm{mg} \mathrm{L}^{-1}$ \\
\hline $\mathrm{SO}_{4}{ }^{2-}$ & 8.8 & $\mathrm{mg} \mathrm{L}^{-1}$ \\
\hline $\mathrm{PO}_{4}{ }^{3-}$ & $\mathrm{BDL}$ & $\mathrm{mg} \mathrm{L}^{-1}$ \\
\hline $\mathrm{Br}^{-}$ & $\mathrm{BDL}$ & $\mathrm{mg} \mathrm{L}^{-1}$ \\
\hline $\mathrm{NO}^{-}$ & $\mathrm{BDL}$ & $\mathrm{mg} \mathrm{L}^{-1}$ \\
\hline & & \\
\hline $\mathrm{NPOC}^{-}$ & 0.87 & $\mathrm{mg} \mathrm{L}^{-1}$ \\
\hline & & \\
\hline $\mathrm{TN}$ & 4.1 & $\mathrm{mg} \mathrm{L}^{-1}$ \\
\hline
\end{tabular}

${ }^{\star} \mathrm{BDL}$ - Below detection limit

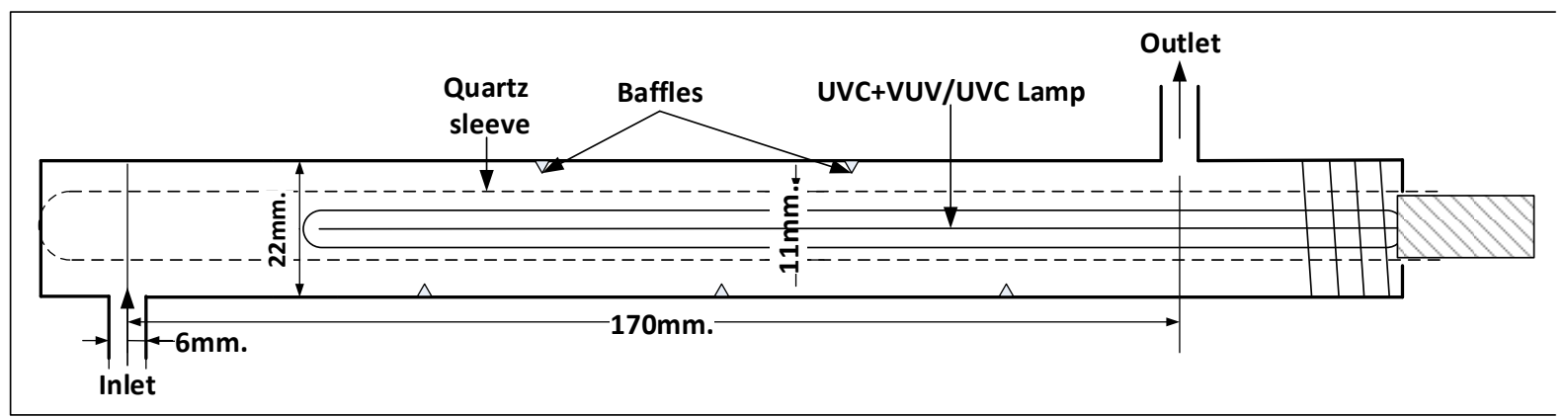

Figure S1: Reactor sketch 


\section{Section S1 - Actinometry results}
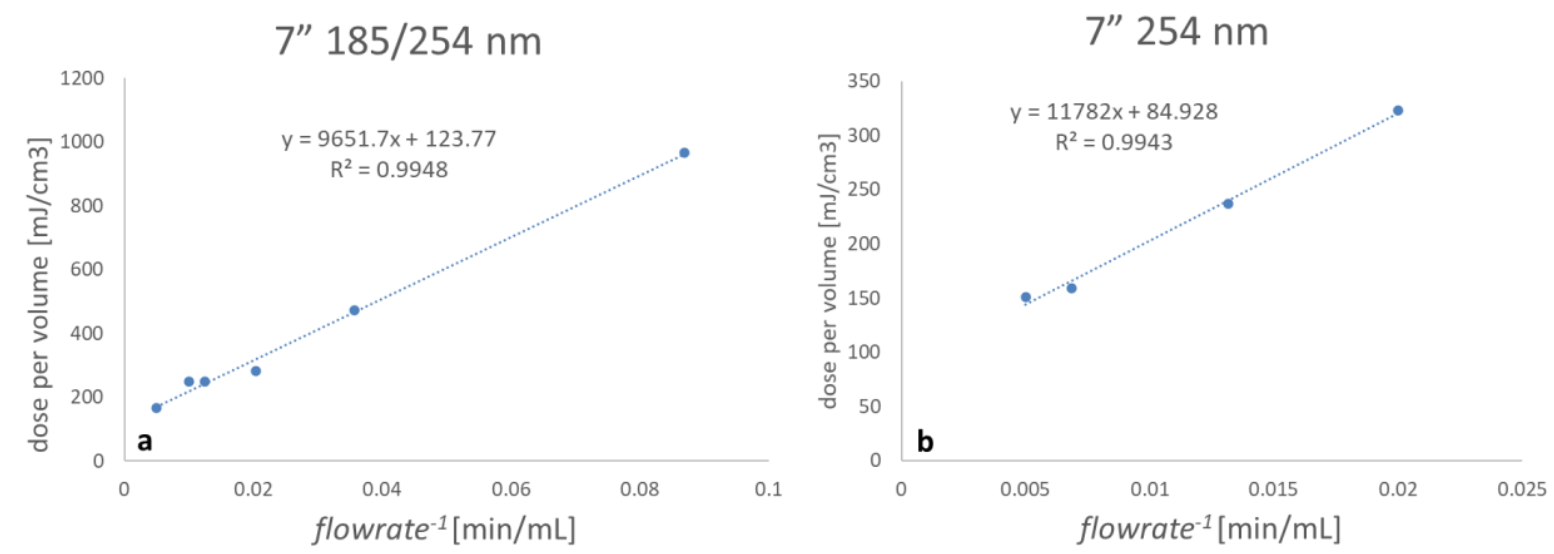

Figure S2: I-/IO3- Actinometry for 7" lamp 185/254 nm (a) and $254 \mathrm{~nm}$ (b)

The average photon fluxes in the reactor (surface area of $41.5 \mathrm{~cm}^{2}$ ) were calculated to be $1.42 \times 10^{-2}$ and $1.47 \times 10^{-2}$ Einstein $\mathrm{s}^{-1} \mathrm{~cm}^{-2}$ for the combined and the $254 \mathrm{~nm} 7$ "-long lamps, respectively. Slightly lower photon fluxes $\left(1.18 \times 10^{-2}\right.$ and $8.67 \times 10^{-3}$ Einstein $\left.\mathrm{s}^{-1} \mathrm{~cm}^{-2}\right)$ were measured for the combined and $254 \mathrm{~nm}$ 4" lamps, respectively, while much lower value

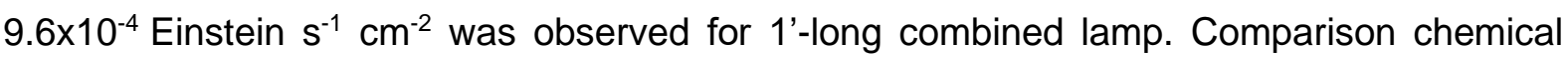
actinometry experiments examining formation of $\mathrm{H}_{2} \mathrm{O}_{2}$ under V-UV radiation (Yang et al., 2018), indicated that photon flux at the $185 \mathrm{~nm}$ wavelength was about $14 \%$ of the total photon flux emitted from the LP-Hg combined lamp (no $\mathrm{H}_{2} \mathrm{O}_{2}$ formation was observed under the 254nm light).

\section{Section S2 - Degradation rates under combined radiation}
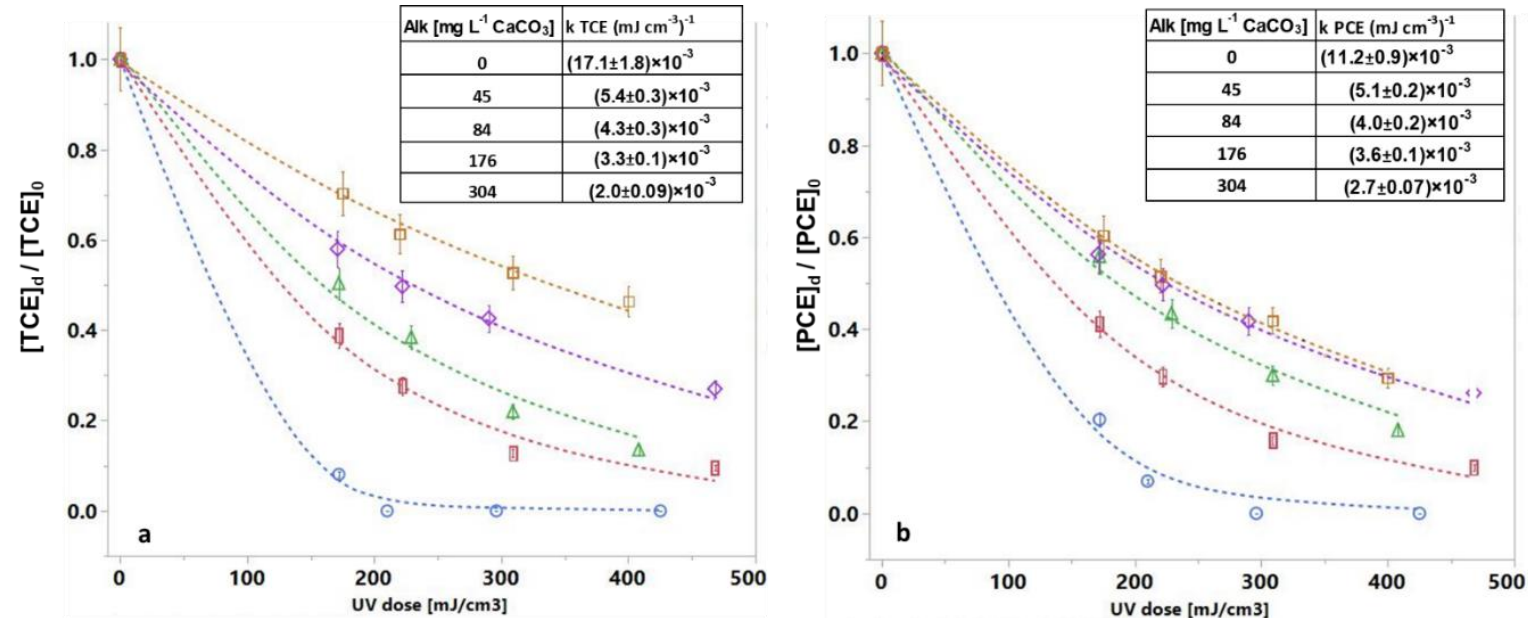

Figure S3: Removal of TCE (a) and PCE (b) as function of UV exposure dose in DIW solutions with different alkalinities [mg/L CaCO3]: 0 (blue circles), 45 (red rectangles), 84 (green triangles), 176 (purple diamonds), 304 (yellow squares). Samples were irradiated by combined 254/185 nm light, and specified doses refer to its $254 \mathrm{~nm}$ moiety. $\mathrm{pH}$ in all carbonate-containing experiments was $\sim 10.3$ and initial concentration $100 \mathrm{\mu g} \mathrm{L}^{-1}$. 
Table S2: Removal kinetics for TCE and PCE for different SO4= concentrations

\begin{tabular}{|c|l|l|}
\hline $\mathrm{SO}_{4}-\left[\mathrm{mg} \mathrm{L}^{-1}\right]$ & $\mathbf{j}$ TCE $\left(\mathrm{mJ} \mathrm{cm}^{-3}\right)^{-1}$ & j PCE $\left(\mathrm{mJ} \mathrm{cm}^{-3}\right)^{-1}$ \\
\hline 0 & $(17.1 \pm 1.8) \times 10^{-3}$ & $(11.2 \pm 0.9) \times 10^{-3}$ \\
\hline 10 & $(21.2 \pm 1.1) \times 10^{-3}$ & $(13.9 \pm 0.8) \times 10^{-3}$ \\
\hline 52 & $(24.4 \pm 0.9) \times 10^{-3}$ & $(14.7 \pm 1) \times 10^{-3}$ \\
\hline 100 & $(19.0 \pm 1.3) \times 10^{-3}$ & $(13.2 \pm 0.7) \times 10^{-3}$ \\
\hline 148 & $(11.0 \pm 0.6) \times 10^{-3}$ & $(10.0 \pm 1.6) \times 10^{-3}$ \\
\hline
\end{tabular}

\section{Section $\mathrm{S} 3$ - OH formation and consumption rates in GW}

Concentration of $\cdot \mathrm{OH}$ radicals is affected by their generation rate via water photolysis and their consumption rate by the various compounds (both pollutants and scavengers; Eq [S1]):

[S1]

$$
\begin{aligned}
& \frac{d[\mathrm{OH}]}{d t}=J\left[\mathrm{H}_{2} \mathrm{O}\right] \\
& -[\mathrm{OH}]\left\{k_{\mathrm{OH}, \mathrm{CO}}^{=}\left[\mathrm{CO}_{3}^{=}\right]-k_{O H, \mathrm{HCO}_{3}^{-}}\left[\mathrm{HCO}_{3}^{-}\right]-k_{\mathrm{OH}, \mathrm{Cl}}^{-}\left[\mathrm{Cl}^{-}\right]-k_{O H, D O M}[\mathrm{DOM}]\right. \\
& \left.-k_{O H, T C E}[T C E]-k_{O H, P C E}[P C E]\right\} \\
& =\frac{J\left[\mathrm{H}_{2} \mathrm{O}\right]}{\left\{k_{\mathrm{OH}, \mathrm{CO}}=\left[\mathrm{CO}_{3}^{-}\right]-k_{\mathrm{OH}, \mathrm{HCO}}^{-}\left[\mathrm{HCO}_{3}^{-}\right]-k_{O H, C l^{-}}\left[\mathrm{Cl}^{-}\right]-k_{O H, D O M}[\mathrm{DOM}]-k_{O H, T C E}[T C E]-k_{O H, P C E}[P C E]\right\}}
\end{aligned}
$$

Nitrate and sulfate are considered to be minor $\cdot \mathrm{OH}$ scavengers and therefore were not included in the equation. On the other hand, direct photolysis of nitrate at $254 \mathrm{~nm}$ is known to yield $\mathrm{OH}$ formation, with yield of 0.09 .

Direct photogeneration rate of $\cdot \mathrm{OH}$ can be calculated based on Eq. [S2]:

$$
[\mathrm{OH}]_{\text {direct photo-formation rate }}=\mathrm{I}_{0}(\lambda) \cdot \varepsilon(\lambda) \cdot[\mathrm{i}] \cdot \Phi_{\mathrm{OH}}(\lambda),
$$

where [i] is the chromophore concentration, $\mathrm{I}_{0}(\lambda)$ is the fluence at wavelength $\lambda, \varepsilon(\lambda)$ and $\Phi_{\mathrm{OH}}(\lambda)$ are, respectively, the chromophor's extinction coefficient and quantum yield for $\mathrm{OH}$ formation at that wavelength.

Eq. S2 can be used to compare the importance of $\mathrm{OH}$ formation via nitrate photolysis at $254 \mathrm{~nm}$ relative to via water photolysis at $185-\mathrm{nm}$. Considering that for $\mathrm{LP}-\mathrm{Hg}$ lamps effluence $\mathrm{I}_{0,185 \mathrm{~nm}} \approx 0.05 \times \mathrm{I}_{0}$ and $\mathrm{I}_{0,254 \mathrm{~nm}} \approx 0.95 \times \mathrm{I}_{0}$, a formation rate of $1.5 \times 10^{-4} \times \mathrm{I}_{0}$ is obtained for 
$30 \mathrm{mg} \mathrm{L}^{-1}$ of nitrate, which is two orders of magnitude smaller than that calculated for water $(55.5 \mathrm{M})$ photolysis: $2.8 \times 10^{-2} \times I_{0}$.

\section{Section S4 - Absorption coefficents and photolysis rates under 254nm radiation}

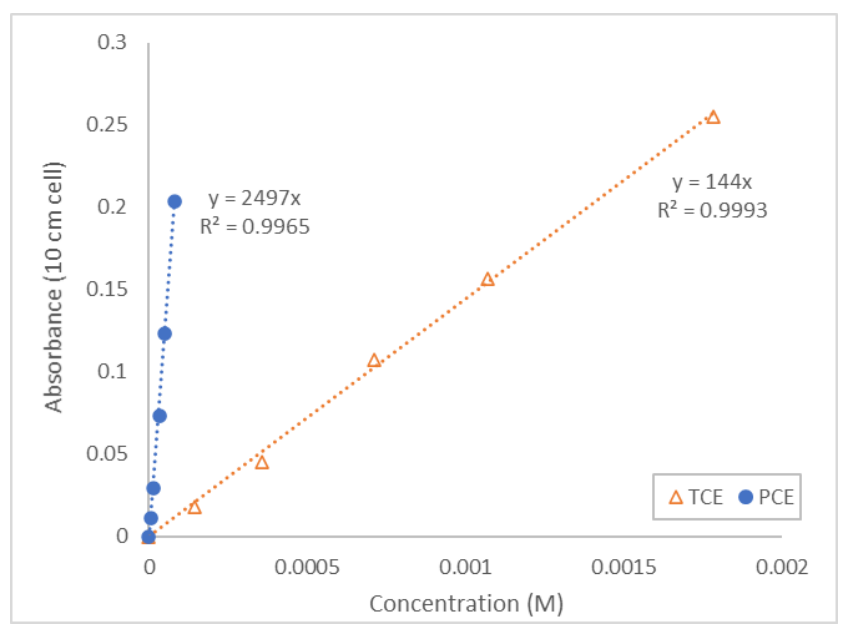

Figure S4- absorbance of TCE (open triangles) and PCE (solid circles) at 254nm wavelength as function of concentrations, indicating molar extinction coefficients of $\sim 15$ and $250 \mathrm{M}^{-1} \mathrm{~cm}^{-1}$, respectively.

Figure S5 depicts observed TCE (a) and PCE (b) degradation under 254-nm irradiation in the presence of nitrate (red diamonds), of sulfate (green triangles), and in clean DIW (clue circles). The faster degradation rates observed in pure DIW than in the presence of nitrate indicate (as discussed above) that the contribution from $\cdot \mathrm{OH}$ generated via nitrate photolysis under UV-C light is negligible, and that nitrate can act as significant inner UV filter. In the presence of sulfate the removal of TCE and PCE did not follow simple $1^{\text {st }}$ order kinetics. This may suggest involvement of chain reactions that are initiated by sulfate photolysis and consiquent formation of sulfate radicals.
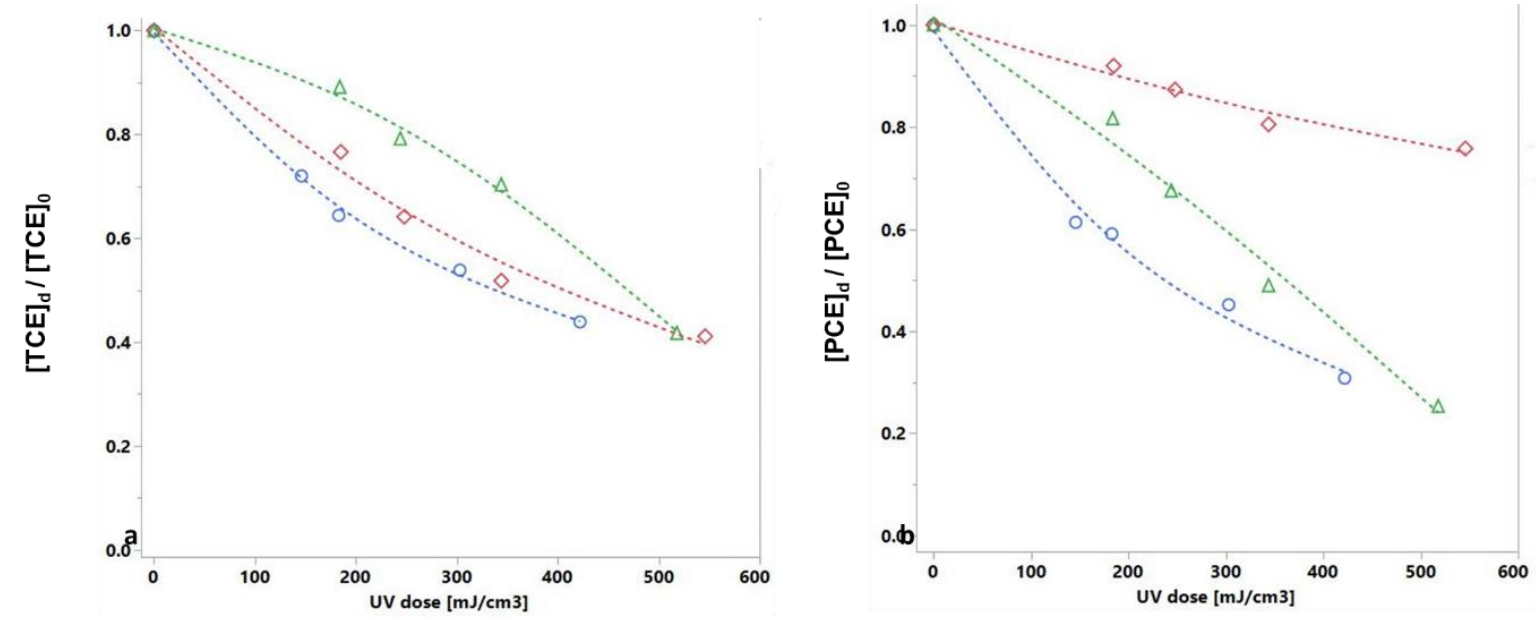

Figure S5: Removal of TCE (a) and PCE (b), with initial concentration about $1 \mathrm{mg} / \mathrm{L}$, in DIW solution (blue circles), DIW solution with addition of $80 \mathrm{mg} / \mathrm{L}$ Nitrate (red diamonds), and in DIW solution with addition of $100 \mathrm{mg} / \mathrm{L}$ sulfate (green triangles) 


\section{$\underline{\text { References }}$}

Yang, L.; Li, M.; Li, W.; Bolton, J. R.; Qiang, Z. A Green Method to Determine VUV (185 Nm) Fluence Rate Based on Hydrogen Peroxide Production in Aqueous Solution. Photochem. Photobiol. 2018, 94 (4), 821-824. https://doi.org/10.1111/php.12913. 